\title{
Putting theory into practice - A case study in one UK medical school of the nature and extent of unprofessional behaviour over a 6-year period
}

\author{
AMANDA HOWE, SUSAN MILES, SARAH WRIGHT \& SAM LEINSTER \\ University of East Anglia (UEA), UK
}

\begin{abstract}
Background: Producing a medical profession which is fit for the demands and expectations of society involves ensuring that practitioners learn what it means to behave in a 'professional' way. Codes of professional conduct have been developed for medical students in the UK, but the literature on how medical schools actually apply these is small. More detail is needed to evaluate approaches to assessing professionalism, or to analyse the extent to which students 'fail' this aspect.

Aim: To describe one UK medical school's approach to monitoring and assessing aspects of professional behaviour; quantify the prevalence and severity of behaviours recognised as cause of concern in the first 6 years of the programme; evaluate whether there is evidence of any association between professional and academic underperformance and draw conclusions for further development of fitness to practice procedures.

Methods: Mixed methods utilising exam board and administrative data for statistical and descriptive analysis.

Results: Even under detailed scrutiny, only 3\% of students received formal warnings for behavioural problems over the course of a 5-year programme, and notifications decreased as students entered the senior years. There was a trend towards association between academic and professional underperformance.

Conclusion: Creating clear expectations, providing positive role models and monitoring student behaviour makes explicit what is expected of students as 'professionals in the making', and contributes to overall low rates of misdemeanour. The predictive value of recurrent and serious behavioural problems is not yet known as it is too soon for these graduates to have established careers. Students who are struggling academically may also present with unprofessional behaviours but the cause of this is unclear. Further research is needed to benchmark systems across the UK, and to know whether formalising expectations of undergraduates result in less problems in subsequent practice.
\end{abstract}

\section{Background - The context}

Professionalism - a set of values, behaviours, and relationships that underpins the trust the public has in doctors (King's Fund 2008) - is complex and multi-dimensional, relating not only to conduct within the doctor-patient relationship, but also to relationships with colleagues, the relationship between the professional and their private self (health, self-discipline), and their responsiveness to the broader service context. Historically, there has been a tendency to emphasise the duty of doctors without full acknowledgement of the social and educational factors which can enable individuals to develop appropriate professional attributes (Cruess \& Cruess 2008). The message that medical educators need to build professional development into their programmes alongside technical knowledge and skills has been highlighted by accrediting bodies throughout the world (American Board of Internal Medicine; Association of American Medical Colleges; Australian Medical Council; Queens University). In the UK, professional leaders, such as Royal College of Physicians

\section{Practice points}

- Developing professionalism in medical students is an essential part of their education.

- Methods include setting clear objectives, specifying behavioural expectations, monitoring these in detail and assessing their achievements.

- This study shows how one UK medical school did this in practice, and how many students had problems during a 6-year period.

- Intervening early may prevent problems later.

- Teaching and monitoring professionalism is timeconsuming and challenging.

(2005), the King's Fund (2008) and the national accrediting body - the General Medical Council (2007) - have set out criteria by which to describe professionalism in medical students. All new UK medical schools had to achieve accreditation of their courses by inspection teams representing 
the GMC, ${ }^{1}$ and this involved scrutiny of how all medical schools were beginning to teach and assess professionalism and fitness to practice (FTP): It is expected that medical schools will set clear outcomes (Table 1), and use these as a basis for assessment (GMC 2009).

However, the contemporary emphasis on why professionalism matters and what is expected is not matched by extensive literature on how to achieve robust professionalism in young doctors, nor on actual performance. Modern approaches to student selection may correlate with later assessment and clerkship performance (Eva et al. 2009), but most admissions procedures have limited ability to select for professionalism, and high scores at admissions do not predict subsequent behaviours in professional domains (Stern et al. 2005). Both students and staff agree that it is important to be specific about what is expected, and give early feedback to improve any problems (Stark et al. 2006). There is evidence that problematic behaviours during medical training are associated with problems in later practice, particularly for those students who are resistant to improvement over time (Papadakis et al. 2005), but how to improve performance in these students is unclear.

There is also controversy over how to make judgements about professionalism, with an emergent emphasis on placement-based assessment (Arnold 2002) and behavioural indicators. Stern et al. (2005) found that, while there was no correlation with admissions and clinical performance, students who did not comply with course requirements for evaluation and occupational immunisation requirements were significantly less likely to do well in subsequent postgraduate clerkship assessments of professionalism: they also appeared to lack insight, being more likely to overrate their own abilities on self-assessment. This suggests that monitoring students' taking of responsibility, compliance with school regulations and insight into own behaviours are important proxies of professionalism. A study by Papadakis et al. (2005) suggests that irresponsible behaviours and poor engagement with the institution predict disciplinary action in postgraduate settings,

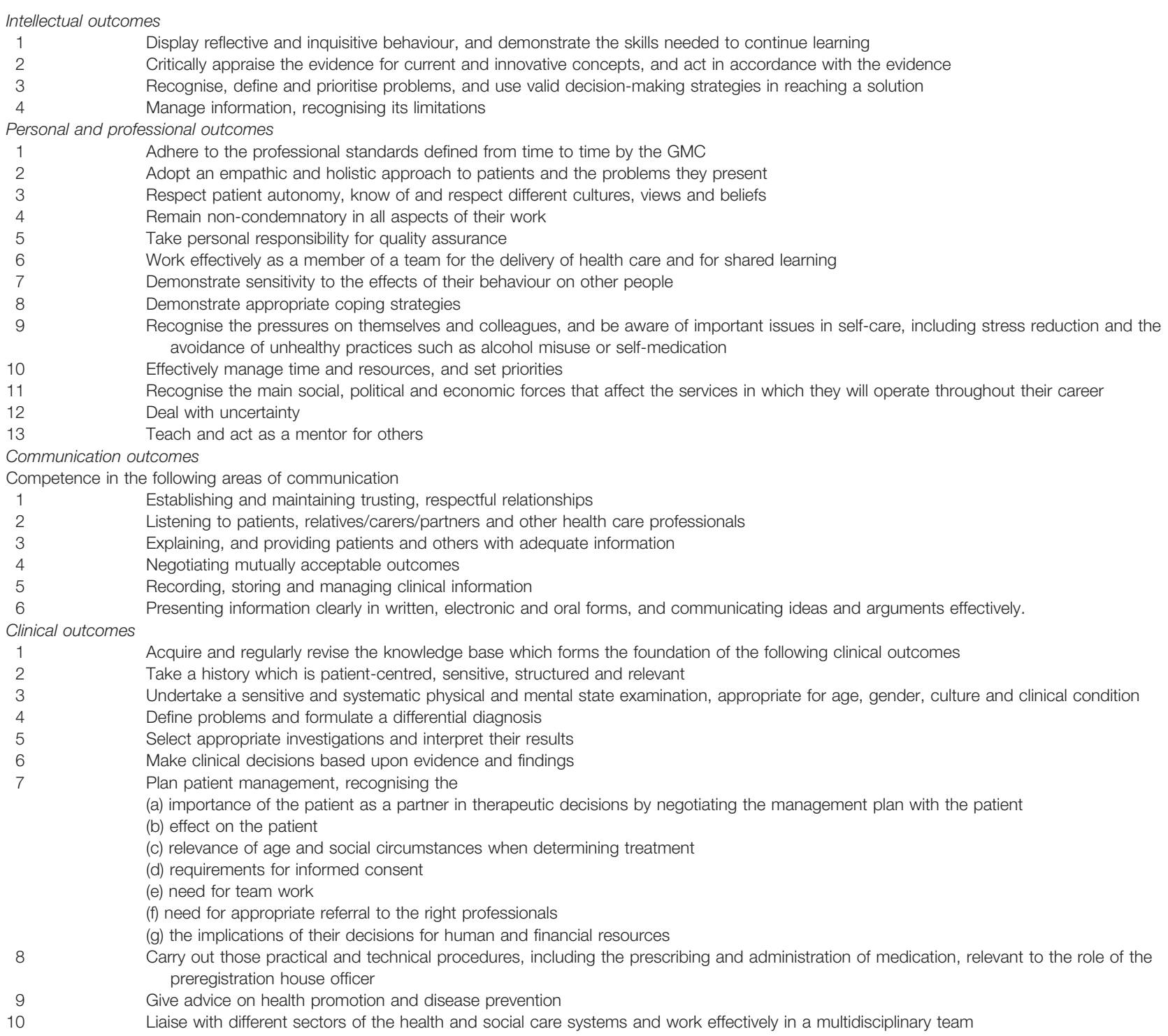


and that students who underperform professionally also tend to have poor academic performance (i.e. a high rate of examination failure).

In the UK, it is left to medical schools to decide how to monitor and make appropriate judgements. They are to decide what thresholds of problem warrant action, and what this action should be - including a full investigation with the sanction of a formal warning which the student must declare at registration, or the ultimate penalty of suspension from medical school if the problems are deemed extreme (GMC 2007). Because of the firmer commitment to monitoring professionalism, any culture among tutors of erring on the side of non-reporting also needs addressing by each school (Cleland et al. 2008).

\section{Background - The programme}

The *****: was one of four new medical schools funded by the Department of Health as a part of an expansion of medical training places in the UK. It had its first intake in 2002, and its first graduates in 2007. The school is relatively small by UK standards, with around 170 students at each intake. ${ }^{2}$ The students have full clinical placements from year 1 through year 5, with no pre-clinical/clinical divide within the curriculum. The students work in groups of 8-10 for problem-based learning and their placements throughout the 5 years of the course: these groups have the same membership for a whole academic year, which demands considerable peer commitment and interaction. Each group has a PBL tutor and a Primary Care tutor who see the students weekly throughout the year, and report formally on their professional behaviours at the end of each semester. There are also named leads for hospital attachments, who can monitor attendance and performance. This makes the students 'visible' to staff, and the continuity of relationship with tutors and peers over a whole year supports a fair assessment of the students' attitudes and behaviour.
The **** MBBS, paralleling the choices made by other educators (Hilton \& Slotnick 2005) established a set of behaviours which we have defined as proxies for professionalism (or unprofessional behaviours), and we can now quantify the extent to which students met or fell below expectations over the first two cohorts over their whole 5-year course. Systematic approaches to professional development in undergraduate programmes is a relatively recent development in the UK, and so we decided to

- describe one UK medical school's approach to developing and assessing professional behaviour the behaviours expected and how they are monitored,

- quantify over a 6-year period (2002-2008) the prevalence and severity of behaviours causing concern,

- evaluate whether there is any association between professional and academic underperformance (Papadakis 2005) and

- draw conclusions for further development of appropriate professionalism development and assessment.

Parker et al. (2008), monitoring performance over time within one component of their course, used behavioural indicators of 'responsibility/reliability', 'participation' 'honesty', 'discrimination' and 'doctor-patient relationship' to assess their students' professionalism. The MBBS core team decided to monitor similar behaviours across all components of the programme within a wide range of staff and settings, using routine data and staff observations. Table 2 shows the areas of behaviour chosen to reflect professionalism domains (which align with the work of Hilton \& Slotnick 2005), and a brief summary of how these are obtained. Students are given extensive advice on what these behaviours mean in practice through the MBBS Course Handbooks, core lectures, tutor input on expectations and ground rules and by formative feedback from peers and staff. Tutors (both campus based and clinical) are trained to monitor these behaviours, and they are also able to consult experienced faculty when

\section{Table 2. Operational behaviours reflecting professionalism domains.}

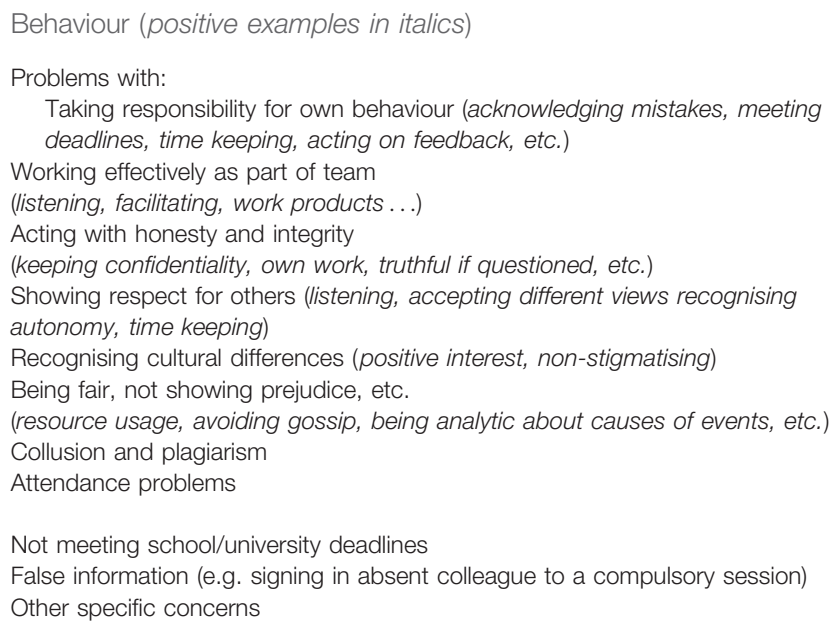

\section{Reporting route}

- Tutor reports (one PBL small group tutor and one GP tutor, varied on an annual basis, each giving two or three summative reports a year)

- Their evidence is based on attendance and behaviours within a group of 10 students working together over an 8-10 week period

- Each aspect is graded excellent, good, needs improvement or unacceptable $^{a}$

Via assessors or tutors to Course Director

Attendance registers all year (judgements relate to total, cause and medical certification)

Reports of defaults from staff affected

By those detecting problem

Staff or student concern form (verbal reports always confirmed in writing) External complaint, e.g. police, health service staff 


\section{Barrier $^{a}$}

Tutor relationship with student Concern about outcome of reporting Pressures from colleagues, peer culture Self-efficacy (confidence)

Skills/knowledge to make judgement Practical constraints, e.g. time

\section{Facilitation}

Tutor reports, others make the judgement and action it

Feedback about GMC expectations, positive feedback when reporting, evidence of support to student Strong culture across school (and nationally) that this is an important thing to do to protect the public Built through training, and tutors can discuss with senior Faculty before they report if they are unsure Through training, experience and staff guidance

Staff concern form is very brief, available and submittable electronically: other reports are part of routine teaching cycle and are also brief.

Note: ${ }^{a}$ Derived from Cleland et al. (2008).

Box 1. Examples of problem behaviours.

Student $\mathrm{X}$, a first year, is reported as unacceptable in taking responsibility and working in a team, because they repeatedly submit work of a poor standard late for their tutorial group. The tutor also notes that they are cutting and pasting work from Internet sites without either citing it properly or 'digesting' it for others to use. The tutor discussed this with the student at week 5 of term but without seeing improvement by week 10. The tutor's diagnosis is 'young, first term, having too much fun, needs to balance work/play'.

Student $Y$, a first year and a mature graduate, has been reported by two members of office staff for failing to attend occupational health assessments, and also by a tutor for poor attendance in primary care. This student had a caution from the police before admission for driving without insurance. When called to meet the Course Director, he claims that it is his 'right' to choose what health care he receives, and that he is already an adult learner and knows what learning experiences he will benefit most. He says that he 'thought the medical school wanted people to think for themselves', and that, as he wants to pursue a career in academic surgery and already works as a volunteer paramedic, the primary care placements are less valuable to him than doing additional laboratory work. Student Z has had a clear record till third year, but is reported by a member of clinical staff for falsifying the signature of a fellow student at a compulsory clinical skills session. The student justifies this by saying that the colleague is having a difficult time and was already in trouble for poor attendance. The student apologises, and suggests in mitigation that they only did it to help a friend to avoid further problems.

Student $Q$ is known to be dyslexic, has had two resitittings to date, and in end of year 2 assessment is found to have plagiarised a substantial part of an essay. They had already submitted extenuating circumstances for the assessment period pleading a chronic illness in their spouse, with additional demands of caring causing impairment to their revision.

Student $\mathrm{P}$ is a high achiever academically, and is also a member of the University Medics Athletics team. S/he has a clear record until year 3 , when she is reported as accepting a caution from the police because of an assault on a member of the public in a nightclub, which resulted in the victim being taken to the emergency department. The details show she had been drinking heavily, and punched another woman several times following a minor provocation witnessed by others.

deciding how to submit evidence. Cleland et al. (2008) found six barriers for tutors when expressing concerns about students: Table 3 shows how our programme attempts to overcome these.

Considerable time is spent both picking up and investigating the facts behind a reported problem before any formal action is taken. For example, essays with group preparation and limited answers are likely to show some similar text, so detailed scrutiny is needed to decide whether plagiarism or collusion has occurred: or, students failing to attend occupational health screens may give good reasons, but are still wasting appointments and staff time if they do not notify in advance. A few examples of 'typical' issues are summarised in the fictional scenarios in Box 1.

Table 4 shows the stages and details of potential penalty. Verified problems are treated cumulatively - so a student who has had previous noted problems may be called to a formal meeting if additional problems arise in other behavioural domains, even if each single incident appears relatively minor. Action may be taken by senior faculty at any time, but decisions on penalties are reviewed and ratified at midyear and end of year 'Progress Boards', where FTP and academic progression are both considered and penalties for problem behaviours recorded (Table 4 and Table 5). At this stage, the student's status can also be reviewed, and further action recommended by the examiners if the overall picture appears to warrant it.

\section{Table 4. Levels of penalty.}

\begin{tabular}{|c|c|}
\hline 1 & Considered - no action needed, or situation resolved \\
\hline 2 & $\begin{array}{l}\text { Noted - letter to student from Course Director, may request or } \\
\text { recommend an action }\end{array}$ \\
\hline 3 & $\begin{array}{l}\text { Recorded - formal (minuted) meeting required with, e.g. Course } \\
\text { Director, Plagiarism Officer, Occupational Health and fol- } \\
\text { lowup letter with expectations }\end{array}$ \\
\hline 4 & $\begin{array}{l}\text { Informal warning - as for } 3 \text {, but notification that further problems } \\
\text { will lead to }\end{array}$ \\
\hline 5 & $\begin{array}{l}\text { First formal warning - has to be declared to the General Medical } \\
\text { Council }\end{array}$ \\
\hline 6 & $\begin{array}{l}\text { Second ('final') warning - has to be declared to the General } \\
\text { Medical Council }\end{array}$ \\
\hline 7 & $\begin{array}{l}\text { Suspension and/or misconduct enquiry - may lead to failure to } \\
\text { qualify. }\end{array}$ \\
\hline
\end{tabular}

Note: Level 3 and upwards would normally be reported to annual Progression Board.

The overall assessment of professionalism rests on the behaviours recorded: students are only allowed to progress to the next year of the course if they achieve passes in all academic components and are deemed to have achieved adequate standards in professional behaviours. A major violation (such as a student falsifying documentation, or being seen misusing technical equipment or premises) may result in a formal warning or even immediate suspension, regardless of previous record. University Fitness Panels and 


\section{Table 5. Profile of behaviours causing concern.}

\section{Problem area}

Tutor reports unsatisfactory behaviour Plagiarism

Collusion

Unexplained/unauthorised absence

Lack of meeting responsibilities

Falsification of signatures

Other behavioural problems (various)

Significant misconduct

Health problems causing FTP problems

Total reported

Total incidents

Notes: ${ }^{2}$ Nineteen of these were coded under two categories - for example, recurrent absenteeism and poor punctuality being the cause of a negative tutor report.

Appeals systems interface with the MBBS procedures, and serious issues will be referred into these.

\section{The sample and ethical issues}

The data for this study are derived from the student records of all those registered on the $* * * *$ MBBS course during the years 2002-2008. All the authors are staff who already had access to these data for assessment purposes: although this meant that specific patterns of problems in the database might be recognised by one or more authors, no one was involved in the study who was not already aware of these problems. Ethical guidance from the **** Faculty of Health Ethics Committee was sought, which advised that research based on data already collected for assessment purposes did not need additional ethics permission if this was fully anonymised. In order to achieve this, data from the course records and Exam Boards (extracted by SW) were entered into a single database using the anonymising eight-digit registration number of each student for reference. Howe checked the data transfer to ensure all students were correctly linked into the new database. The students were then given a new identifier within the database and their original ID deleted. This appears similar to the basis of Stern's (2005) study.

\section{Results}

The data presented includes:

- a description of how professionalism is monitored processes, criteria and penalties,

- prevalence of professional behaviour problems reported in Progress Committees and Exam Boards over the 6-year period (2002-2008) and

- statistical analysis of relationship between professional and academic problems in the last 2 years (2006/2007 and 2007/2008).

\section{How many students were noted for behavioural problems?}

Table 6 shows that, over the 6-year period when a total of 803 students entered the $* * * *$ MBBS course, there were a total of
176 incidents. These related to the behaviours of 118 students (15\%). The demographics of the students concerned are shown in Table 6: there were no significant differences in terms of age of students with behavioural issues, but students who are admitted from regional 'access' courses (which offer 1 year pre-admission programmes to candidates without senior school science qualifications) are somewhat over-represented in reports, and women relatively under-represented, compared to the student body as a whole.

Forty-one (5\%) students had more than one issue raised under professionalism concerns. Typically these were separate incidents, but could be causally related: for example, receiving an unsatisfactory tutor report after having been recurrently absent or late without cause. Twenty-six students had two incidents, nine had three incidents, and six (under $1 \%$ of all students) had four incidents. Only 25 students (3\%) reached the level of informal or formal warning in this 6-year period (12 formal, 10 informal and 3 unspecified). Only one student was withdrawn from the course in this period on FTP grounds.

\section{Patterns of student problems}

Over the 6 years, approximately equal numbers of notifications occurred in years 1 and 2, with some fall-off thereafter over years 3-4, and very low numbers in the final year (Table 7). To explore any overlap between students experiencing behavioural problems and academic problems, we took the last 2 years' assessment periods (2006/2007 and 2007/2008) when the school had reached a full 5 years of students, and analysed the relationship between academic passes at first sitting and any record of a behavioural problem (by chi-square). The total number of students taking the assessments in 2007/2008 was 699 (5 years of students from 2003/2004 intake onwards). Eighty-eight students had had a record of at least one behavioural incident to date (30 students had graduated the previous year, hence the total of 118 drops to 88 ). Of these, $67 \%$ passed their assessment and 33\% were referred for a fail in one or more components at first sitting. Seventy-seven percent of students passed with no history of any 'FTP' reports, while $23 \%$ had to resit. Chi-squared tests showed a non-significant tendency for students recorded for unprofessional behaviours to be more likely to be resitting exams (chi-square $=4.197, \mathrm{df}=1, p=0.056$ ).

However, looking within each year, the association appears to be significant (Table 8): that is, a student presenting with some kind of behavioural problem is more likely to perform badly in academic assessments in that year. During 2007/2008 alone, 21 students were presented to FTP boards, of whom only $48 \%$ passed the year at first sitting: as opposed to $77 \%$ of 'non-FTP' students who passed at first sitting. This difference was statistically significant, and the same was true for the previous year (2006/2007).

\section{Discussion}

There are a number of limitations to this study. We have not attempted a full statistical analysis of factors associated with behavioural problems, as the numbers are very small. We do not attempt to predict factors affecting longer term 
Table 6. Sociodemographic profile at course entry: comparing students causing concern to whole cohort.

\begin{tabular}{|c|c|c|}
\hline Sociodemographic factors at entry to course & Whole student population (total 803) & Causing concern (total 118) \\
\hline Age range (years) & $17-57$ & $17-49$ \\
\hline Age mean (years) & $23.47, \pm 6.58 \mathrm{SD}$ & $24.32, \pm 6.81 \mathrm{SD}$ \\
\hline Age mode & 18 & 19 \\
\hline \multicolumn{3}{|l|}{ Educational background } \\
\hline - School leaver & - $370(46 \%)$ & - $48(41 \%)$ \\
\hline - Access course (preadmissions science) & - $148(18 \%)$ & - $30(25 \%)$ \\
\hline - Graduate & - $278(35 \%)$ & - $40(34 \%)$ \\
\hline - Unclassified & - $7(1 \%)$ & \\
\hline \multirow[t]{2}{*}{ Sex ratio } & $62 \%$ female & $49 \%$ female (total 58 ) \\
\hline & $38 \%$ male & $51 \%$ male (total 60 ) \\
\hline
\end{tabular}

Table 7. Number of students reported in each academic year, by year group.

\begin{tabular}{|c|c|c|c|c|c|c|c|c|}
\hline Year & 2002/2003 & 2003/2004 & 2004/2005 & 2005/2006 & 2006/2007 & 2007/2008 & Total & Percentage of year \\
\hline 1 & 8 & 3 & 8 & 7 & 13 & 13 & 52 & 6.48 \\
\hline 2 & & 9 & 13 & 20 & 9 & 4 & 55 & 8.59 \\
\hline 3 & & & 10 & 5 & 2 & 5 & 22 & 4.65 \\
\hline 4 & & & & 7 & 2 & 10 & 19 & 5.51 \\
\hline 5 & & & & & 1 & 2 & 3 & 1.40 \\
\hline Total & & & & & & & 151 & \\
\hline Cohort number & 105 & 110 & 130 & 128 & 167 & 163 & 803 & \\
\hline
\end{tabular}

Notes: Cohort number indicates the number starting in the first year for each academic year. Percentage column shows the number of students reported to FTP in each year group as a percentage of the number who have studied that year (e.g. $52 / 803 \times 100=6.48 \%$ for year 1 ). The absolute number of students with reports against their name is 118 - the greater total of reports overall in this table (151) is because some students are reported multiple times.

Table 8. Analysis of academic ${ }^{a}$ and behavioural problems in assessment.

\begin{tabular}{|lcccc|}
\hline & $\begin{array}{c}\text { Number of } \\
\text { students with } \\
\text { behavioural } \\
\text { problems }\end{array}$ & $\begin{array}{c}\text { Percentage of } \\
\text { pass:fail for students } \\
\text { with behavioural }\end{array}$ & $\begin{array}{c}\text { Percentage of } \\
\text { pass:fail for } \\
\text { students with no }\end{array}$ \\
Cohort & 27 & problems & behavioural problems & Chi-square \\
$2006 / 2007$ & 21 & 33 (pass): 67 (refer) & 79 (pass): 21 (refer) & $30.282, \mathrm{df}=1, p<0.001$ \\
$2007 / 2008$ & 48 (pass): 52 (refer) & 77 (pass): 23 (refer) & $9.512, \mathrm{df}=1, p=0.007$ \\
\hline
\end{tabular}

Notes: 'Academic performance' denotes an overall pass at first sitting for all exam components in that year; 'refer' means that student will have to resit one or more of their exams, which could be written, clinical or project based on any of our 5 years.

performance: our first graduates are only just entering postgraduate training. Other authors have noted the problems of making robust assessments (Papadakis et al. 2005), and also the problems of intervening effectively with students to develop genuine (rather than mechanistic) professional motivation and insight. We have not included here the students' perspectives on whether it is helpful to have their behaviours brought under scrutiny (Brainard \& Brislen 2007), nor do we have space to discuss the complex issues raised when making the judgements summarised in Table 2 (Rees \& Knight 2007). We have some experience of students with criminal convictions on record, but none of serious problems occurring within the course. Nor do we have any evidence of how being reported may feed forward into professional practice, although other authors have identified similarities between behavioural problems in students and practising clinicians (Ainsworth \& Szauter 2006).
The rates of misdemeanour are similar to those found in Parker et al.'s (2008) study, where 19\% all students had some kind of incident, $5 \%$ had formal interviews, only 4 (less than $1 \%)$ were referred to their board of examiners, and two students 'failed a year for persistent unprofessional behaviour'. The apparent reduction of problems as students progress through the course has three possible explanations: 'protoprofessionalism', 'pseudo-professionalism' or 'protocollegiality'. The first of these reflects Hilton and Slotnick's work (2005), suggesting there may be a learning curve for students as they mature and come to understand the behavioural expectations of the school and the profession; greater skills of self-management and higher stakes for failure encourage better performance in the later years. Students could perhaps also become adept at avoiding the behaviours which will cause them problems while retaining negative attitudes - being 'pseudo-professional': this is hard to detect, 
but also hard to sustain. Third, 'pseudo-collegiality' denotes that clinical tutors with a more dominant role in later years may be more reluctant to report students who they recognise as future colleagues, and give them more leeway as autonomous adults (Cleland et al. 2008). The last explanation is less likely at **** as the students have prolonged contact with clinical tutors in clinical placements from year 1 onwards and do not have a more dominant role in later years. Because of the intensive vigilance (Bentham 1995) ${ }^{3}$ from multiple sources of data triangulated in our professionalism monitoring, and because of the cultural expectations of professional conduct by both nonclinical and clinical tutors, we think underdetection and underreporting are both unlikely.

We have made some changes to our system over time: it is a challenge to get tutor feedback and attendance data from hospital placements with multiple activities and staff leads, but we have increased our monitoring of attendance data, though remain open to student challenge both on grounds of accuracy ( I did attend, perhaps I forgot to sign the register...) and justice (other people missed things but they didn't get caught...). We now hold a quarterly 'Professionalism Committee' in order to create more systematic review and governance of problems, and have an MBBS Professionalism Lead to oversee curriculum and assessment in this domain. Ensuring that students are given a fair hearing while keeping issues confidential requires discipline and self-control by all, and the usual issues of 'whistle-blowing' and its difficulties apply for staff and peers who feel concerned about a student's perceived behaviours (Coull 2008). Sharing information about problems is also contentious, though the educational and professional rationale for this is clear (Cleary 2008).

To summarise, the behaviours and means of monitoring these aligns with recommendations by regulating bodies and the choices made by other medical schools, and the order of magnitude of students with problems appears similar to other articles describing systemic monitoring. Further research is indicated by these findings into the following: the effectiveness of early monitoring and guidance on professionalism in reducing problems in practice: the predictive value of various levels of behavioural concern for postgraduate practice; and the implications of any association between academic and professional problems, which may both reflect other contributory factors, such as health or personal problems. The relationship between behaviour and penalty needs further evaluation for 'proportionality', to reflect the recent GMC expectations that students who receive a formal warning will have to disclose this at registration.

\section{Conclusion}

In conclusion, the system which has developed over the last 6 years at **** has many features of that recommended by the GMC, and it is also guided by university regulations. There is an emerging possibility that, given clear guidance and early 'low- level' warnings, students learn rapidly to avoid repeated errors. Consistent procedures and proportionate responses are part of showing students how to behave professionally, and few students have reached the 'formal warning' stage by the end of the course. We are interested to see how other schools operationalise their professional behaviour and FTP judgements, and look forward to being able to see long-term predictors of professional problems in practice.

\section{Acknowledgements}

The authors acknowledge the contribution of Dr Sandra Gibson (UEA) to providing background detailed sociodemographic data: the huge amount of work put in by UEA MBBS administrative staff in recording and following up data which contributes to the accurate detection and management of problems: also to the academics who spend time picking up and advising students about areas they need to improve.

Declaration of interest: This was unfunded research undertaken to reflect on and share learning from the experiences of our own programme. There is no material or professional conflict of interest for any author.

\section{Notes on contributors}

AMANDA HOWE, MA, MD, MEd, FRCGP, FAcadMEdEd, a lead author, had the original idea for the article, was lead academic for professionalism and managed many of the situations in the article.

SAM LEINSTER, BSc, MD, FRCS (Ed \& Eng), SFHEA, FAcadMED, was Dean until late 2010, advised on the article and similarly has been involved both in the development and administering of the systems described.

SARAH WRIGHT, BA (Hons), is a lead administrator for the course and collated the data from the student records and exam boards.

SUSAN MILES, CSci, BA, PhD, is a lead researcher for data from our MBBS, who anaonymised the data and led the statistical analyses.

\section{Notes}

1. Details of the UK accreditation scheme can be found at http://www.gmc-uk.org/education/undergraduate/qabme_ programme.asp, downloaded 1 January 2010.

2. This was less in the first intakes, hence lower overall numbers in these results.

3. Akin to Bentham's 'Panopticon', where people in an institution can be unknowingly observed at all times from any angle.

\section{References}

Ainsworth MA, Szauter KM. 2006. Medical student professionalism: Are we measuring the right behaviors? A comparison of professional lapses by students and physicians. Acad Med 81:S83-S86.

American Board of Internal Medicine [Accessed 2010 January 29]. Available from: http://www.abim.org/default.aspx

Arnold L. 2002. Assessing professional behavior: Yesterday, today, and tomorrow. Acad Med 77:502-515.

Association of American Medical Colleges [Accessed 2010 January 29]. Available from: http://www.aamc.org/medicalschools.htm

Australian Medical Council [Accessed 2010 January 29]. Available from: http://www.amc.org.au/index.php/ar/bme

Bozovic M. 1995. The panopticon; or, The inspection house (1787). In: Miran Bozovic, editor. The panopticon writings by Jeremy Bentham. London: Verso. pp 29-95.

Brainard AH, Brislen HC. 2007. Viewpoint: Learning professionalism: A view from the trenches. Acad Med 82:1010-1014. 
Cleary L. 2008. "Forward feeding" about students' progress: The case for longitudinal, progressive, and shared assessment of medical students. Acad Med 83:800.

Cleland JA, Knight LV, Rees CE, Tracey S, Bond CM. 2008. Is it me or is it them? Factors that influence the passing of underperforming students. Med Educ 42:800-809.

Coull R. 2004. Blowing the whistle. Student BMJ 12:64-65.

Cruess SR, Cruess RL. 2008. Understanding medical professionalism: A plea for an inclusive and integrated approach. Med Educ 42:755-757.

Eva KW, Reiter HI, Trinh K, Wasi P, Rosenfeld J, Norman GR. 2009. Predictive validity of the multiple mini-interview for selecting medical trainees. Med Educ 43:767-775.

GMC 2007. Medical students: Professional behaviour and fitness to practice. London: General Medical Council.

GMC 2009. Medical students: Professional behaviour and fitness to practise London: General Medical Council. Available from: http://www.gmcuk.org/static/documents/content/GMC_Medical_Students.pdf. Accessed 12 August 2010

Hilton SR, Slotnick HB. 2005. Proto-professionalism: How professionalisation occurs across the continuum of medical education. Med Educ 39:58-65.
King's Fund 2008. Understanding doctors: Harnessing professionalism. London: King's Fund.

Papadakis MA, Teherani A, Banach MA, Knettler TR, Rattner SL, Stern DT, Veloski JJ, Hodgson CS. 2005. Disciplinary action by medical boards and prior behavior in medical school. N Engl J Med 353:2673-2682.

Parker M, Luke H, Zhang J, Wilkinson D, Peterson R, Ozolins I. 2008. The "pyramid of professionalism": Seven years of experience with an integrated program of teaching, developing, and assessing professionalism among medical students. Acad Med 83:733-741.

Queens University, Kingston, ON, Canada [Accessed 2010 January 29]. Available from: http://meds.queensu.ca/medicine/obgyn/pdf/ CanMEDS_2005_Framework.pdf

Rees CE, Knight LV. 2007. The trouble with assessing students' professionalism: Theoretical insights from sociocognitive psychology. Acad Med 82: 46-50.

Royal College of Physicians 2005. Doctors in society: Medical professionalism in a changing world. Report of a Working Party of the Royal College of Physicians of London. London: Royal College of Physicians (RCP)

Stark P, Roberts C, Newble D, Bax N. 2006. Discovering professionalism through guided reflection. Med Teach 28:e25-e31.

Stern DT, Frohna AZ, Gruppen LD. 2005. The prediction of professional behaviour. Med Educ 39:75-82. 